\title{
Calcium isotope response of Morozovella spp. to Paleocene-Eocene Ocean Acidification
}

\author{
GABRIELLA D. KITCH ${ }^{1}$, ANDREW D. JACOBSON ${ }^{1}$, \\ MATTHEW T. HURTGEN ${ }^{1}$, BRADLEY B. SAGEMAN ${ }^{1}$, \\ DUSTIN T. HARPER ${ }^{2}$, JAMES C. ZACHOS ${ }^{3}$ \\ ${ }^{1}$ Department of Earth and Planetary Sciences, Northwestern \\ University, Evanston, IL \\ (gabby@earth.northwestern.edu) \\ ${ }^{2}$ Department of Geology, The University of Kansas, \\ Lawrence, $K S$ \\ ${ }^{3}$ Department of Earth and Planetary Sciences, University of \\ California Santa Cruz, Santa Cruz
}

The calcium isotope composition $\left(\delta^{44 / 40} \mathrm{Ca}\right)$ of primary carbonate producers may be sensitive to ocean acidification (OA). OA during the Paleocene Eocene Thermal Maximum (PETM) provides an opportunity to examine the calcium isotope response of calcifiers during reduced biocalcification. We generated the first high-resolution, high-precision planktic foraminiferal $\delta^{44 / 40} \mathrm{Ca}$ records before and across the PETM to test for OA signals. Our records employ specimens of Morozovella spp. collected from Ocean Drilling Program Sites 1209 (Shatsky Rise, Pacific) and 1263 (Walvis Ridge, Atlantic). At Site $1209, \delta^{44 / 40} \mathrm{Ca}$ values start at $-1.33 \%$ during the upper Paleocene and increase to $-1.15 \%$ $250 \mathrm{kyr}$ prior to the carbon isotope excursion (CIE). Values remain elevated through the PETM interval and decrease into the earliest Eocene. A shorter-term record for Site 1263 shows a similar trend, although $\delta^{44 / 40} \mathrm{Ca}$ values are on average $0.22 \%$ lower and decrease more rapidly after the CIE onset. Coherent, but offset, secular trends are consistent with a kinetic isotope effect, whereby calcite $\delta^{4 / 40} \mathrm{Ca}$ values inversely correlate with precipitation rate. Geologically rapid $\mathrm{Ca}$ isotope shifts before and across the PETM appear to reflect response of Morozovella to globally-forced changes in the local carbonate geochemistry of seawater. All data combined suggest that the PETM OA event occurred near the peak of a gradual reduction in seawater $\mathrm{pH}$ and $\left[\mathrm{CO}_{3}{ }^{2-}\right]$ during a time of elevated atmospheric $p \mathrm{CO}_{2}$ driven by North Atlantic Igneous Province (NAIP) emplacement. 